\title{
Research on Task-based Culture Course Model for Postgraduates Based on Social Constructivist Theory
}

\author{
Ling Cui \\ Department of Foreign Languages and Cultures, Kunming University of Science and Technology, Kunming
}

(561572834@qq.com)

\begin{abstract}
The dual goal of language teaching to accomplish both humanistic and instrumental purposes is particularly significant in culture course. To achieve the combination of the two aspects, so as to improve learners' cultural awareness and intercultural communication competence, this research builds a systematic and effective course model based the Social Constructivist Theory and Task-base Language Teaching.
\end{abstract}

Keywords - Culture course, Social Constructivist Theory, Task-base Language Teaching

\section{社会建构主义理论指导下的任务型研究生文化课程教 学模式研究}

\author{
崔凌 \\ 昆明理工大学, 昆明, 云南, 中国
}

\begin{abstract}
摘 要 语言教学“人文性”和“工具性”的双重目标在文化课程中尤为显著, 如何实现二者的结合, 以培养学生的文化意识, 提高 跨他们的文化交际能力, 是当下文化教学的重点和难点。社会建构主义理论为实现文化教学的双重目标提供了原则上的指导, 而任务 型语言教学则为实践这些原则提供了载体。本文根据研究生的学习需求和特点, 从教学内容、教学形式和方法以及教学评价三方面, 在社会建构主义理论的指导下, 将任务型教学引入传统讲座课堂, 构建了一套系统有效的文化教学模式。
\end{abstract}

关键词 文化课程, 社会建构主义, 任务型语言教学

\section{1. 引言}

外语教学中, 语言和文化是密不可分的。上世纪 20 年 代, 胡适在《归国杂感》中就已经指出, “我们学习西洋文 字, 不单是要认得几个洋字, 会说几句洋话, 我们的目的 在于输入西洋的学术思想。所以我认为中国学校教授西洋 文字, 应该用“一箭双雕”的方法, 把“思想'和“文字”并教”[1]。 当今, 文化教学已成为语言教学中不可割裂的一部分。《英 语课程标准》中明确指出义务教育阶段的英语课程具有 “工 具性”和“人文性”双重性质。虽然文化教学的重要性已被广 泛接受, 并在很多大学都开设了英美文化、西方文化等课 程以增强学生的文化意识, 提高他们的跨文化交际能力, 但实际教学效果却不乐观。张红玲 2000

昆明理工大学研究生百门核心课程建设项目 (资助号: 10998083)
年对上海外国语大学英语、经贸、经济法、新闻传播四个 学院的 204 名英语专业及复合型英语专业学生进行文化教 学测试, 结果发现“英语学习者的语言知识技能和文化知识 技能之间存在着相当大的差距” [2]。究其原因, 文化课程普 遍采用了用目的语传授文化知识点的教学模式, 这些零散 的知识点仅仅是术语的翻译和表层文化现象的灌输, 使得 学生既不理解表层现象后的深层原因, 也不会在跨文化交 际中采取正确的交际策略。文化教学的目的不在于“术语” 和“知识”的掌握, 而是使学生将所学的文化知识内化为“文 化意识”, 并借助这种文化意识能够用目的语对各种文化现 象进行独立的思考和探究, 应用于实际的跨文化交际中。 本研究旨在建立一定的教学模式, 寻找“内化”途径, 实现 “人文性”和“工具性”的双重目标。 


\section{2. 社会建构主义理论和任务型教学法对文化教学的 启示}

社会建构主义 (Social Constructivist Theory) 认为知识 不是由他人传递的, 而是由个人以自己的经验背景为基础, 在与他人的交往互动中主动构建的（Williams \& Burden, 2000）[3]。SCT对文化教学模式的建立有着很好的指导作 用: 第一, SCT重视学习过程, 而反对简单的知识传递, 从根本上解释了现今文化教学效果不佳的原因, 为建立新 的教学模式提供了基本思路; 第二, SCT将学习理解为主 动构建意义的过程, 这为如何将文化知识内化为文化意识 指明了道路; 第三, SCT强调学习和发展是社会和合作活 动, 可用于指导课堂环境的建构; 第四, SCT突显了学习 者个人的经验背景和学习的个人意义, 对如何使学习过程 充满真实的个人意义提出了要求。

$\mathrm{SCT}$ 为我们寻找的教学模式提供了原则上的指导, 而 任务型语言教学 (Task-based language Teaching) 为实践这 些原则提供了载体——任务（Nunan, 2012）[4]。首先, TBLT“做中学”的理念提高了学习者的主动性和参与性。在 完成任务的过程中, 学习者必须将新的文化知识与个人知 识背景和经历相结合, 在真实世界中寻找并构建现实意义 和个人意义, 从而将文化知识内化为文化意识; 其次, 任 务需要以小组合作的形式, 在与外界环境的互动中完成, 任务的完成过程不仅是成员间交流协作的过程, 也是成员 和外界环境互动的过程; 第三, 任务的考核既关注结果, 也关注过程, 还要求学生进行互评和自评。因此考核也是 建构的一部分, 同时进一步加强了学习者间的互动, 以及 个人意义的实现。

\section{3. 教学模式}

\section{1 教学对象和目标}

本门课程的授课对象大多为理工科背景的全日制硕士 研究生。他们较本科生而言, 思想更为成熟和系统化, 思 考和分析能力也更趋完善。他们对英语的需求, 也从日常 交流扩展到了思想、学术等深层次的交流。针对这些特点 和需求, 我校研究生公共英语课程分为两个阶段, 上学期 统一开设综合课程, 加强学生听、说、读、写、译五个基 本技能的训练; 下学期开设英美文化、科技翻译、学术交 流等选修课程, 让学生根据自身的兴趣和需求自由选择。

英美文化课旨在提高研究生英语语言技能、拓展英语文化 知识、培养他们对文化现象的分析和思考能力、帮助学生 建立起一定的文化意识, 以满足他们将来可能面对的日常 交际和学术交流的需求。但是, 面对多为理工背景的研究
生, 在短短 18 周 36 学时实现以上目标是一个巨大的难题和 挑战。

\section{2 教学内容}

文化这个概念包罗万象, 若是想面面俱到, 不仅会使整个 课程形如散沙, 而且止于浅表。为了在短时内实现教学目 标, 我们的教学内容重在“核心文化”, 即两个源头, 一条 主线。现代西方文化的两个源头, 古希腊罗马文化和基督 教文化, 塑造了西方文化的基本特征, 与现代西方社会的 政治制度、经济体制、思想信念、典章制度、节庆习俗、 礼仪规范等等都有密切的渊源关系 (赵林, 2010) [5]。对 这两个源头有所了解, 学习者可对西方文化有整体上的把 握, 并能对各种文化现象从源头上进行分析和解释。西方 文化的形成同时又是一个变化着的漫长历史过程, 其间发 生的重大事件对整个文化的形成有着重要的影响。但是我 们关注的不是历史事件本身，而是其对文化进程的影响。 因此, 教师可根据自己的擅长领域或者学习者的专业特点, 选取一条贯穿历史的主线, 如“哲学史”、“文学史”、“艺术 史”等, 分析其整体发展历程。“两头一线”的核心文化不仅 能使学习者对西方文化有系统性认识, 更能培养他们的分 析和思考能力。有了“核心文化”作为框架和分析工具, 其 后的内容的就非常便于梳理了, 可根据需要拓展文化其它 方面的内容。图 1 可用以形象地描述这种“两头一线多分支” 的教学内容安排。

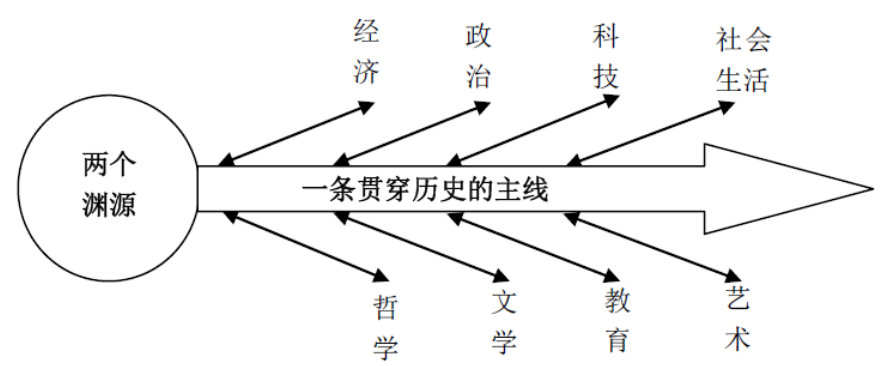

图 1 鱼骨型文化教学内容

\section{3 教学形式和方法}

西方现存的文化教学方案可归纳为三种类型: 以知识 为基础的外加型方案 (explicit cultural teaching)、以行为为 重点的融合性方案 (implicit cultural teaching)、以及以意义 为中心的综合性方案 (synthetic approach) (陈申, 1999) ${ }^{[6]}$ 。 国内的文化课程一般采用第一种类型, 教师通过讲座集中、 高效、系统地传递文化知识。学习者在学习过程中可以快 速吸收这些知识, 但是往往没有机会结合个人经验对这些 信息进行深度处理, 因此, 这些缺乏个人意义的知识或者 很快被遗忘, 或者形成文化定式 (cultural stereotype), 反 
而有可能阻碍了跨文化交际。第二种类型倡导学习者通过 真实的交际, 在行动中学习文化。这种在“做中学”的方法 能够让学习者身历其境地体验文化, 并有效提高跨文化交 际能力, 但是对交际环境的要求高, 而且学习者在短期内 也很难对文化有一个系统整体认知。第三种方案是对前两 种方案的取长补短, 在系统文化知识的基础上探讨文化现 象背后的意义, 并应用于真实的跨文化交际中。

综合考虑方案的效果和可行性, 第三种方案无疑是现 阶段最佳的选择。我们的具体做法是将TBLT与讲座相结 合, 根据两个阶段教学内容的不同特点, 在不同的教学法 指导下进行:

(1) 核心文化: 以讲座为主, 任务为辅, 在支架式和 随机通达教学法的指导下进行。

核心文化的讲座部分遵循支架原则, 一步一步地为学 生的学习提供适当的、小步调的线索和提示 (支架), 让学 生通过这些支架逐步攀升, 培养对文化现象的思考和分析 能力, 最终搭建起基本的知识系统框架。

但是由于文化的复杂性, 在讲座这一单一情境下学习 容易形成文化定式。因此, 可以以任务为辅助, 在随机通 达原则的指导下, 针对同一主题, 让各个小组多渠道获得 不同情境的资料，从不同的角度共同进行意义建构。多情 境的综合呈现, 能够培养学生的发散思维和批判思维, 使 学生对文化知识进行立体多元的建构。随机通达原则指导 下的任务也是被分解的小任务, 各个小组在这一阶段每次 只需负责一个情境下的资料搜集和呈现，因此可以逐步增 强语言应用能力和交流信心，为下一阶段的大型任务做好 准备。

(2) 拓展部分: 以任务为主, 讲座为辅, 在抛针式教 学法的指导下进行。

拓展部分, 教师简单讲解主线和要点, 主要让学生通 过任务进行实战训练, 通过语言的实际应用和真实的跨文 化交际解决问题。“抛针”即“确定问题”。抛针原则指导下 的任务为复杂的大型任务, 要求各个小组在特定文化主题 下寻找感兴趣的问题, 一旦确定问题, 所有的学习活动都 围绕着问题确定下来。这些学习活动在课下真实的环境中 进行，主要包括多渠道的资料搜集和真实的跨文化交际， 成员既有分工又要合作，最终亲身体验从识别目标到达到 目标的全过程。

在支架教学法、随机通达教学法和抛针式教学法指导 下的文化教学具有难度适中、脉络清晰、渠道多样、实践 性强的特点。讲座与任务的交叉实现了理论和实践、“人文 性”和“工具性”的结合, 是文化知识内化为文化意识的必经 之道。

\section{4. 评价}

文化学习的过程是复杂多元的, 因此评价也应是多方 位的。评价系统既应包括形成性评价, 也应包括总结性评 价; 既有教师评价, 也需要学习者的自评和互评。

(1) 总结性评价: 在一个学期的学习活动结束后, 学 生需提交一篇论文。论文是对整学期学习效果的最终评价, 检查学习者是否能够在了解西方文化发展基本脉络的背景 下, 对特定的文化现象进行思考和分析, 并提出自己的独 特见解。

（2）形成性评价: 形成性评价在整个教学过程中以小 组为单位进行, 最主要的部分是每周的知识竞赛和每章节 的大型任务展示。知识竞赛的目的是检查学习者对讲座的 理解掌握以及课后的复习工作, 将枯燥的记背改造为紧张 的竞赛, 不仅能提高学习积极性, 还可以活跃氛围, 增强 团队凝聚力。大型任务展示是学习者独立学习、实践活动 的集中体现, 是创造性思考和分析能力的综合展示, 更是 团队协作、集体智慧的成果。形成性评价以团队评价为主、 个人评价为辅, 目的是降低学生的学习焦虑, 鼓励团队精 神。

（3）教师评价, 学习者的自评和互评: 主要针对大型 任务的评价。学习者在任务的完成过程中需记录任务日志, 详细记录下完成任务的过程, 遇到的问题和困难以及解决 办法, 并对自己和其它成员的表现进行评价。在任务展示 中, 各个小组对还要对展示组的作品进行从内容、形式、 结构和语言四方面给出评分和评价。这些评价作为大型任 务的评价参考纳入最终评价。

\section{5. 结语}

语言教学“工具性”和“人文性”的双重目标在文化教学 中显得尤为突出, 如何将零散的文化知识内化为文化意识, 提高学生的跨文化交流能力成为当下文化教学的重点和难 点。强调个人意义建构和社会互动的社会建构主义理论为 文化课程的新模式提供了原则性指导, 而任务型教学则为 实践这些原则提供了载体。任务型文化课程教学模式(图2) 从教学内容、教学形式和方法, 以及教学评价三方面进行 了全方位的设计, 旨在通过语言实践将文化知识内化为文 化意识, 以提高学生的思考、分析和实践能力。

本模式为文化教学提供了一种新的视角和框架, 但还 需在大量教学实践的基础上进行进一步细化和完善, 特别 是讲座内容、任务设计和评价标准, 还需要进一步实践性 的探索和验证。 


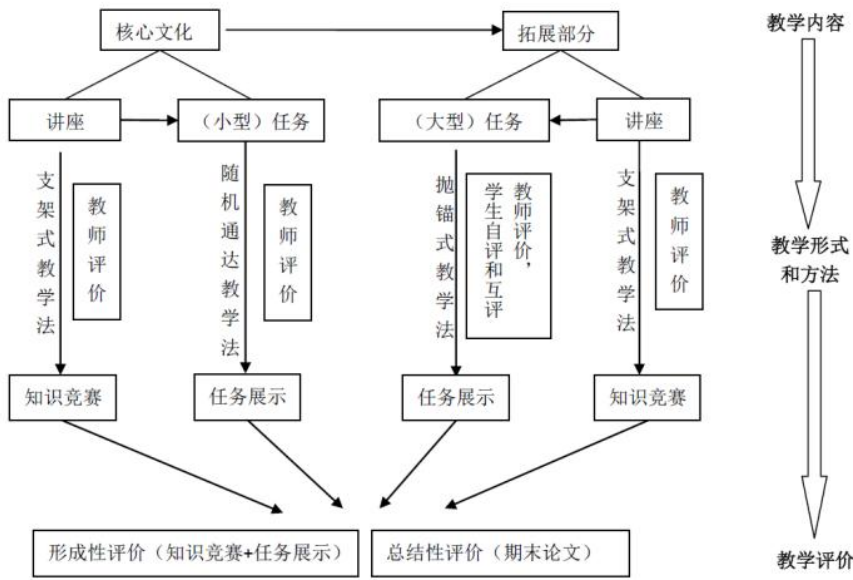

图 2 任务型文化课程教学模式

\section{参考文献(References)}

[1] $\mathrm{Hu}$ Shi. Collected Works of $\mathrm{Hu}$ Shi Volulme II. Beijing University Press, 1998: 471-472

[2] Zhang Hongling. Foreign Language Teaching Reform in China From Cross-Culture Perspective - the Status Survey of Culture Teaching in Foreign Language Teaching in China. //Wu Youfu. The Research of Foreign Language and Culture. Shanghai Foreign Language Education Press, 2001: 332-346

[3] Marion Williams \& Robert L. Burden. Psychology for Language Teachers. Foreign Language Teaching and Research Press, October, 2000:42-43

[4] David Nunan. Task-Based Language Teaching. Foreign Language Teaching and Research Press, 2012: 49-165

[5] Zhao Lin. Introduction to Western Culture. Higher Education Press, 2010: 88

[6] Chen Shen. The Teaching of Cultures in Foreign Language Education. Beijing Language and Culture University Press 1999: $51-120$ 